\title{
The Effect of Technological Parameters on the Microstructure and Mechanical Properties of AlSi17Cu4 Alloy
}

\author{
Jarosław PIĄTKOWSKI ${ }^{1}$, Robert WIESZALA ${ }^{2}{ }^{*}$, Marta ZIEMNICKA-SYLWESTER ${ }^{3}$ \\ ${ }^{1}$ Department of Materials Technology, Faculty of Materials Science and Metallurgy, Silesian University of Technology, 8 \\ Krasińskiego Str., 40-019 Katowice, Poland \\ ${ }^{2}$ Faculty of Transport, Silesian University of Technology, 8 Krasińskiego Street, 40-019 Katowice, Poland \\ ${ }^{3}$ Division of Materials Science and Engineering, Faculty of Engineering, Hokkaido University, Kita 13 Nishi 8, Kita -Ku \\ 060-8628 Sapporo, Japan \\ cross'ref http://dx.doi.org/10.5755/j01.ms.22.3.8490
}

Received 17 October 2014; accepted 17 May 2015

\begin{abstract}
The mechanical properties (HB, HV, $\left.R_{0.2}, R m\right)$ and plastic properties $\left(A_{5}, Z\right)$ of $\mathrm{AlSi} 17 \mathrm{Cu} 4$ alloy when exposed to chosen technological processes, such as modification, overheating and rapid cooling, are presented in this paper. The best combination of properties was noticed in alloy overheated for 40 minutes at $920^{\circ} \mathrm{C}$ and casted into a metallic mould submerged in liquid nitrogen. Moreover, the technological stability and homogeneity of alloys were evaluated based on spread of results, expressed by standard deviation. It was proven, based on microstructure analysis, that the best effect of refinement was achieved by intensive cooling of alloy preceded by its overheating. The XRD analysis indicated that the intermetallic phases, mainly $\theta\left(\mathrm{Al}_{2} \mathrm{Cu}\right)$ and $\gamma_{1}\left(\mathrm{Al}_{4} \mathrm{Cu} 9\right)$ caused hardening of the solution, improvement in mechanical properties and technological stability.

Keywords: casting, Al-Si alloys, crystallisation, mechanical properties.
\end{abstract}

\section{INTRODUCTION}

The Al-Si alloys are under consideration for aerospace and land transport due to high strength-to-weight-to-cost ratio. However, coarse-grained microstructure in these alloys obtained by casting has negative effect on the mechanical properties and ability to machining. That is why the significant objective is to obtain fine microstructure. It can be achieved by modification of the chemical composition [1-4], application of electromagnetic field [5], overheating of liquid alloy far beyond liquidus temperature [6-9], and through rapid cooling $[10-15]$. It happens due to creation of significantly larger number of crystallisation nuclei and, as a result, improved homogeneity of alloy and decreased average grain sizes in material after heat treatment.

The parameters which particularly determine the structure of alloys and, as the result, their final properties, are overheating temperature and cooling rate. The combination of these two technological treatments decreases the intensity of structural defects and, in a significant way, broadens the range of application possibilities in designing and exploitation of Al-Si-Me alloys fabricated by casting. Moreover, dynamic crystallisation enables precipitation hardening and, by melting, homogenisation and crystallisation of phases containing alloy additives. The size of Si-crystals precipitates which affect the migration of grain boundaries in the matrix, containing $\alpha(\mathrm{Al})+\mathrm{Si}$ eutectics is significant to ensure high structural stability of the material. It can be observed not only at room temperature, but also at elevated temperature, which is particularly important in wear

\footnotetext{
* Corresponding author. Tel.: +48-32-603-44-53; fax: +48-32-603-4292

E-mail address: Robert.Wieszala@polsl.pl (R. Wieszala)
}

environment of casted alloys, working often under tough conditions, like in land and air transport.

Additional hardening of the Al-Si alloys can be achieved by various alloy elements additions [16-17]. The most extensively investigated is the effect of copper (responsible for $\mathrm{A} 12 \mathrm{Cu}$ ) or magnesium which corresponds to $\mathrm{Mg}_{2} \mathrm{Si}$ formation. However, the effect of magnesium addition fades after heating up the material to $250{ }^{\circ} \mathrm{C}$ (working temperature of pistons), therefore copper as an additive has potentially broader practical application. The element does not only enhance the mechanical properties but also significantly improves machinability [18] due to grain refinement. This is of significant importance because of strict requirements concerning the condition of surface roughness and dimensional accuracy of cast pistons.

In order to improve the durability of drive and breaking system modules which are mostly exposed to extensive use in transport it is necessary to modify the composition and conditions for the alloy preparation. The results discussed in this paper are focused on hypereutectic alloy $\mathrm{Al}-\mathrm{Si}-\mathrm{Cu}$, which was exposed to overheating and rapid cooling, and is used in automotive and aviation industry to produce heavily loaded casts of internal combustion engines, blocks and bodies of cylinders in compressors, pumps, brakes and connectors [18].

The enhancement of mechanical and plastic properties was based on theory of $\alpha(\mathrm{Al})$-solution hardening and occurrence of precipitates. It was achieved by overheating of liquid alloy much beyond liquidus temperature [19-21], holding at such temperature and then rapid cooling of melted alloy casted into a mould submerged in liquid nitrogen. Such technology caused the grain refinement in the microstructure and significantly improved investigated mechanical properties [22]. The proposed concept should additionally ensure improved 
homogeneity of the material, repeatability of microstructure features, which means better material and technological stability.

\section{EXPERIMENTAL PROCEDURE}

\subsection{AlSi17Cu4 alloy preparation}

A standard hypereutectic AlSi17Cu4 alloy, fabricated in laboratory under conditions similar to series A3XX.X type A390.0 described in ASTM (American Society for Testing and Materials) specification and ASME (American Society of Mechanical Engineers), was chosen for the investigations. The alloy was melted from bulk elemental materials: aluminium AR1 (99.96\% Al), technical silicon (98.95\% Si), and electrolytic copper $(99.98 \% \mathrm{Cu})$. Small portions of silicon were dosed to liquid aluminium melted in a $\mathrm{SiC}$ crucible (volume of $1500 \mathrm{~cm}^{3}$ ) and about 45 minutes later copper was added into the bath. The AlSi17Cu4 alloy was melted under protective coating made of $\mathrm{NaF}+\mathrm{KCl} \quad(20: 80 \mathrm{wt} . \%$ respectively), in inductive furnace Balzers VSG. In order to achieve optimal thermodynamic equilibrium, the temperature and holding time were optimised experimentally (about $800{ }^{\circ} \mathrm{C}$ for $40 \mathrm{~min}$ ). Before casting from temperature of about $780{ }^{\circ} \mathrm{C}$ the alloy was refining using $0.3 \mathrm{wt} . \%$ of commercial "Rafglin-3" $\left(\mathrm{K}_{2} \mathrm{TiF}_{6}+\mathrm{C}_{2} \mathrm{Cl}_{6}+\mathrm{Na}_{2} \mathrm{SiF}_{6}\right)$ and $10 \mathrm{~min}$ later the slag was removed from the top surface of the alloy. Chemical composition of the investigated alloy after purification is presented in Table 1.

Table 1. Chemical composition of AlSi17Cu4 alloy

\begin{tabular}{|l|c|c|c|c|c|c|c|}
\hline \multirow{2}{*}{ Alloy } & \multicolumn{7}{|c|}{ Chemical composition (wt.\%) } \\
\cline { 2 - 8 } & $\mathrm{Si}$ & $\mathrm{Cu}$ & $\mathrm{Fe}$ & $\mathrm{Mn}$ & $\mathrm{Mg}$ & $\mathrm{Ni}$ & $\mathrm{Al}$ \\
\hline AlSi17Cu4 & 16.49 & 3.85 & 0.21 & 0.01 & 0.02 & 0.01 & Balance \\
\hline
\end{tabular}

Several series of samples were prepared and then exposed to different processes:

- chemical modification using casting alloy CuP10, (about $10 \mathrm{wt} . \%$ of P), or

- overheating of liquid alloy to the temperature of $920^{\circ} \mathrm{C}$, homogenisation by holding at such temperature for $40 \mathrm{~min}$. and casting into a conventional casting mould, or

- overheating of alloy with further chemical modification using $\mathrm{CuP}$, or

- overheating of alloy, modification and casting into a permanent mould submerged in liquid nitrogen.

The 3 samples of AlSi17Cu4 alloy with size of $\varnothing 20 \times 160 \mathrm{~mm}$ fabricated according to above-mentioned technology were prepared simultaneously, in one casting process. In order to achieve maximum cooling rate, the steel permanent mould was inserted into stainless steel mantle container using graphite sheet lagging. Such whole device was put into a ceramic container. The liquid nitrogen was poured into that container (Fig. 1 a) and after that the samples for static tensile test (Fig. 1 b) were casted into the steel permanent mould. The process was repeated in order to produce 18 samples for each technology, and then, based on EN 10002-1, casted samples were exposed to machining to fulfil the size requirements described in the engineering standard.

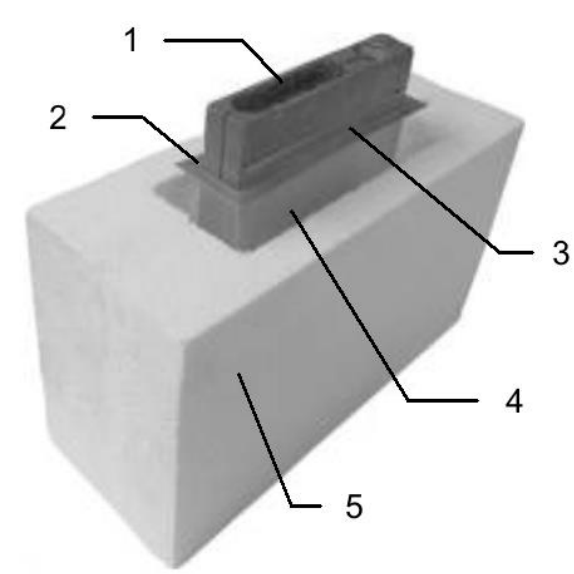

a

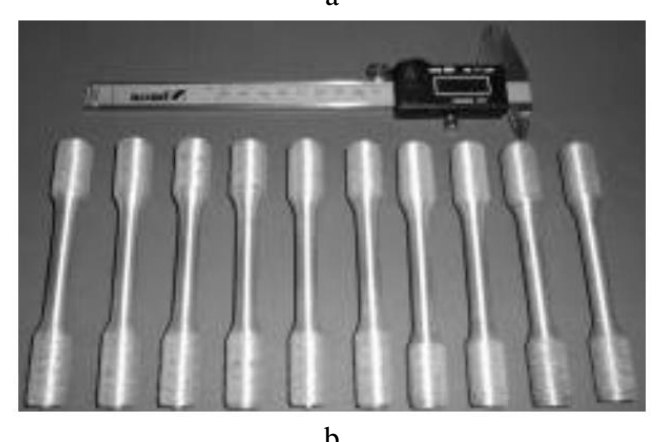

Fig. 1. Samples preparation for static tensile test: a-casting mould cooled down by liquid nitrogen; 1-steel permanent mould; 2 -mantle made of stainless steel plate; 3 -graphite sheet lagging; 4-liquid nitrogen; 5-ceramic container; $b$ - as-cast samples for mechanical tests

\subsection{Characterisation of alloys}

The tensile tests were conducted using Intron 3382 with transmission ratio of $20: 1$ and constant tension speed of $5 \mathrm{~mm} / \mathrm{min}$. Static tension test at room temperature was performed in accordance to EN ISO 6892-1. Based on those results the tensile strength $\left(R_{m}\right)$ was determined, together with conventional yield strength $\left(R_{0.2}\right)$, ultimate strength $A_{5}$ and relative contraction $(Z)$ for sample after rupture. The Brinell hardness measurements were conducted using hardness tester Zwick ZHF, under load of $187.5 \mathrm{~kg}$, using stainless steel ball $\varnothing 2.5 \mathrm{~mm}$ for $35 \mathrm{~s}$, in compliance with EN ISO 6506-1. The Vickers hardness was determined under load of $30 \mathrm{~kg}(294 \mathrm{~N})$ for $15 \mathrm{~s}$ according to EN ISO 91/H-04355 engineering standard. The hardness was measured at room temperature on flat, polished surfaces where diameter of pores was not bigger than $2.5 \mu \mathrm{m}$. The test was repeated 8 times, each time the two extreme results were discarded and from the remaining ones arithmetic mean and standard deviation were calculated. The Vickers micro-hardness $\mu \mathrm{HV}_{100}$ was determined under load of $100 \mathrm{~g}$ for $15 \mathrm{~s}$, using hardness tester Duramin A-300 by Struers. The arithmetic mean was calculated from 8 measurements for each structural phase ( $\mathrm{Si}$ grains, matrix, and precipitates containing $\mathrm{Cu}$ ), each time discarding two extreme results.

The mechanical properties evaluated for investigated materials were discussed in respect to microstructure, which was observed using both optical and scanning electron microscopy. Metallographic sections were 
prepared by grinding with $\mathrm{SiC}$ papers and then final polishing with diamond paste finishing with grains of $1 \mu \mathrm{m}$ in size. The micro-sections were etched with $0.5 \% \mathrm{HF}_{\mathrm{aq}}$ solution.

The phase composition was investigated using X-ray diffractometer (JEOL JDX-7S) with copper anode.

\section{RESULTS}

\subsection{Mechanical properties}

In order to ensure representative results, 18 samples (for each of considered technologies plus preliminary condition), were prepared by casting with further machining and then subjected to mechanical tests. The statistical calculations (mean value, variance, and standard deviation) were performed for 16 results, discarding the two extreme one. The spread of results expressed by standard deviation is shown on the graphs (Fig. 3-Fig. 6) as an error bars. The Brinell hardness as well as Vickers hardness and microhardness, depending on applied technology, are presented in Fig. 2. and Table 2.

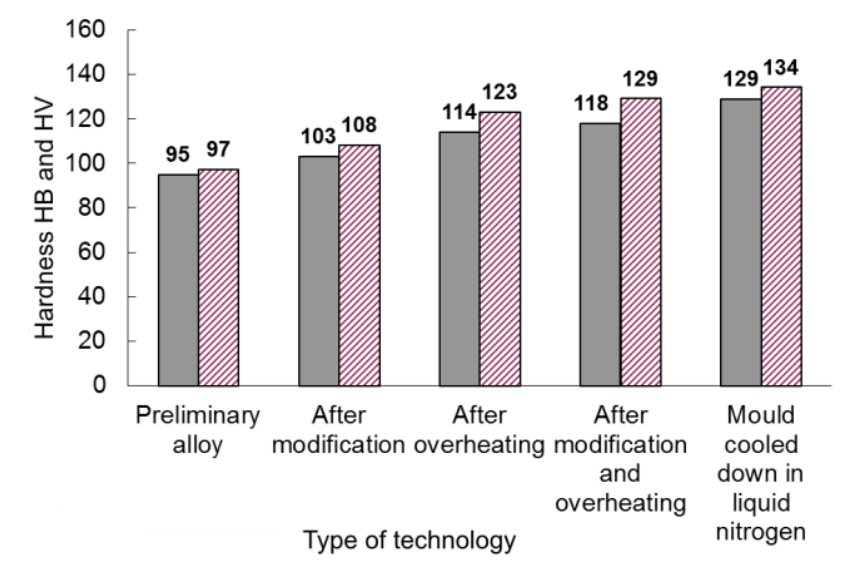

Fig. 2. Brinell hardness $(H B)$ (grey bars) and Vickers hardness (HV) (striped bars) for investigated materials obtained using different technologies

Table 2. Vickers microhardness $\mu \mathrm{HV}_{100}$ for structural phases of tested alloy

\begin{tabular}{|c|c|c|c|c|c|c|}
\hline \multirow{3}{*}{$\begin{array}{l}\text { Type of } \\
\text { technology }\end{array}$} & \multicolumn{6}{|c|}{ Vickers hardness $\mathrm{HV}_{100}, \mathrm{HV}$} \\
\hline & \multicolumn{2}{|c|}{$\begin{array}{c}\alpha(\mathrm{Al}) \\
\text { matrix }\end{array}$} & \multicolumn{2}{|c|}{$\begin{array}{c}\mathrm{A}(\mathrm{Al})- \\
\theta\left(\mathrm{Al}_{2} \mathrm{Cu}\right) \\
\text { eutectics }\end{array}$} & \multicolumn{2}{|c|}{ Si crystals } \\
\hline & Mean & $\mathrm{SD}, \%$ & Mean & $\mathrm{SD}, \%$ & Mean & $\mathrm{SD}, \%$ \\
\hline Primary condition & 75 & 13 & 96 & 14 & 1011 & 7 \\
\hline After modification & 73 & 12 & 99 & 13 & 1026 & 6 \\
\hline After overheating & 78 & 10 & 94 & 11 & 1020 & 8 \\
\hline $\begin{array}{l}\text { After modification } \\
\text { and overheating }\end{array}$ & 78 & 11 & 100 & 9 & 1018 & 6 \\
\hline Mould in nitrogen & 76 & 8 & 102 & 8 & 1014 & 9 \\
\hline
\end{tabular}

The most essential increase in hardness (both $\mathrm{HB}$ and HV) comparing to non-modified condition was observed for samples which underwent overheating to temperature of $920^{\circ} \mathrm{C}$, modification with $\mathrm{CuP}$ foundry alloy, and then rapid cooling. Such technology caused about $36 \%$ improvement in $\mathrm{HB}$ and about $38 \%$ for $\mathrm{HV}$, comparing to initial conditions. High hardness was also achieved for alloys exposed to overheating (114 HB and $123 \mathrm{HV})$ and overheating with modification (118 HB and $129 \mathrm{HV})$, respectively. Moreover, small spread of results (SD in the range of $4-8 \%$ ) confirmed structural homogeneity of tested materials. It proved high metallurgical stability of the conducted technological processes. It is probably caused by overheating far beyond liquidus temperature $T_{\text {liq }}$. Since random inclusions were melted, uncontrolled heterogeneous nucleation of silicon could be avoided. According to Vickers microhardness results (Table 2.), all phases coexisting in the material, even $\alpha(\mathrm{Al})$, exhibited enhanced hardness comparing to pure $\mathrm{Al}$, for which hardness does not exceed $50 \mathrm{HV}$ [23].

Hardness and micro-hardness measurements confirmed the effect of both solution and precipitation hardening. The $\alpha(\mathrm{Al})-\mathrm{Si}$ eutectics exhibited hardness which was elevated comparing to matrix, while the hardest phase was $\mathrm{Si}$, as could be expected. No micro-hardness measurements were conducted for multi-component eutectics which contained $\theta\left(\mathrm{Al}_{2} \mathrm{Cu}\right)$ and $\gamma_{1}\left(\mathrm{Al}_{4} \mathrm{Cu}_{9}\right)$, because too small precipitates were observed. The significantly reduced load during investigations would need to be applied which would certainly affect the results. The copper-based intermetallics should also reveal hardness higher than for pure aluminium. However, their influence on hardness in those alloys is insignificant due to low volume fraction of those precipitates which is caused by small copper content in investigated alloys.

In respect to applied technological processes, the materials after chemical modification, overheated and then rapidly cooled down have shown the best effects of precipitation hardening. Those materials were characterised by the highest hardness of both matrices and eutectics. Such effect was not confirmed in case of microhardness of silicon crystallites which is caused by smaller sizes of those crystallites and at the same time stronger effect of soft matrix. Slightly lower micro-hardness values measured for silicon crystals compared to hardness of those crystals in samples prepared using other technologies confirm reduction in the grain size for silicon crystallites. At the same time, it should be expected that the average sizes of crystallites of other phases present in the material will be also reduced.

The results of tensile strength $\left(R_{m}\right)$ have shown that application of melting technology with overheating caused significant increase in mechanical strength. For samples which underwent intensive cooling $R_{m}$ equals $311 \mathrm{MPa}$ (48\% increase) and $297 \mathrm{MPa}$ (42\% increase) for samples after overheating and chemical modification in comparison to initial condition (Fig. 3).

Insignificantly lower value of $R_{\mathrm{m}}(276 \mathrm{MPa})$ was noticed in samples overheated to $920^{\circ} \mathrm{C}$, but without modifications. However, overheating process improved the homogeneity of the material, and as a result decreased the spread of results of tensile strength $(\mathrm{SD}=4 \%)$.

Increase in hardness and tensile strength, particularly for samples which underwent fast crystallisation, can also be explained by significant amount of frozen crystals in castings. Those are equiaxial crystals with random orientation of arrangement, which provide macroscopic isotropy and relatively good homogeneity. Ingots with such structure have therefore better mechanical properties and are more beneficial materials in further processing. Due to fine microstructure better fracture toughness is also 
expected. The mechanical properties were also characterised based on conventional yield strength $\left(R_{0.2}\right)$, while plastic properties of tested materials were discussed based on ultimate strength $A_{5}$ as well as relative contraction of sample after rupture $(Z)$.

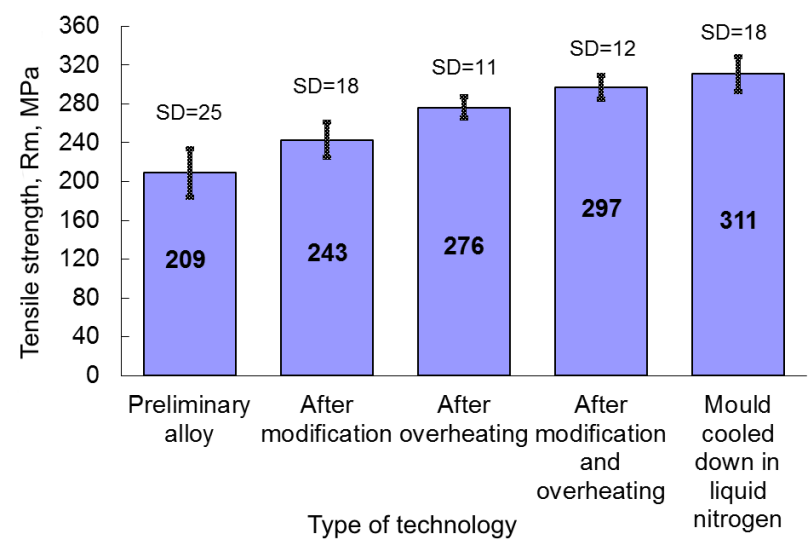

Fig. 3. Tensile strength $R_{m}$ depending on applied technology

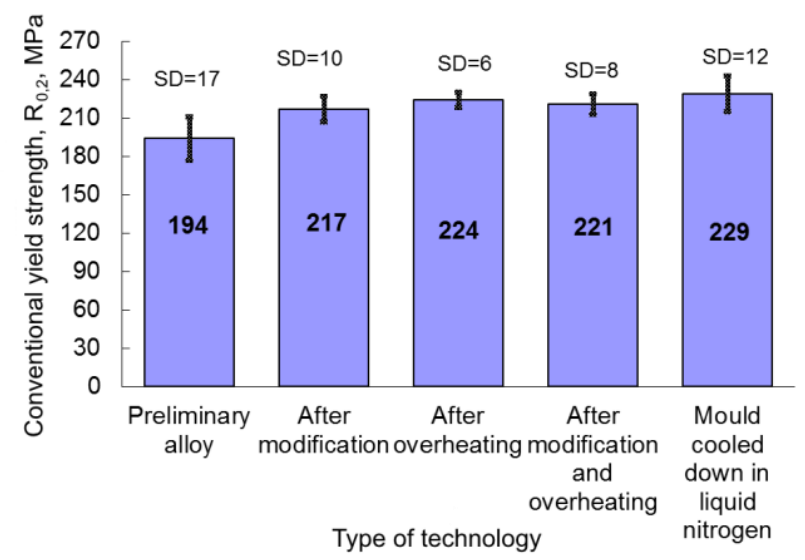

Fig. 4. Conventional yield strength $R_{0.2}$ depending on applied technology

Both modifications of composition and overheating caused the increase in conventional yield strength $R_{0.2}$ by almost $12-15 \%$ when compared to initial material (Fig. 4).

The combination of those two technological processes with rapid cooling in mould cooled down with liquid nitrogen enhanced the effect and the increase of $12 \%$ in $R_{0.2}$ was achieved, comparing to initial material. This improvement of Young's modulus also confirms high efficiency of applied processes. However, similarly to tensile strength, the smallest spread of tested properties was observed for samples after overheating, which may prove that overheating process causes homogenisation of structure in liquid phase and at the same time significantly influences technological stability. Similar tendency was observed for results of ultimate strength and contraction after rupture (Fig. 5, Fig. 6).

Experimental values of $A_{5}$ have shown that each of applied technological treatments caused increase of ultimate strength after rupture by at least $67 \%$ which should be the effect of better homogeneity of the material when compared to initial alloy. This fact can also be confirmed by decreased spread of results. At the same time the lowest ultimate strength and the most visible contraction resulted by rupture (Fig. 5 and Fig. 6) for materials prepared using those three technological processes had proven the increase in elastic properties (Young's modulus $E$, shear modulus $G$ ).

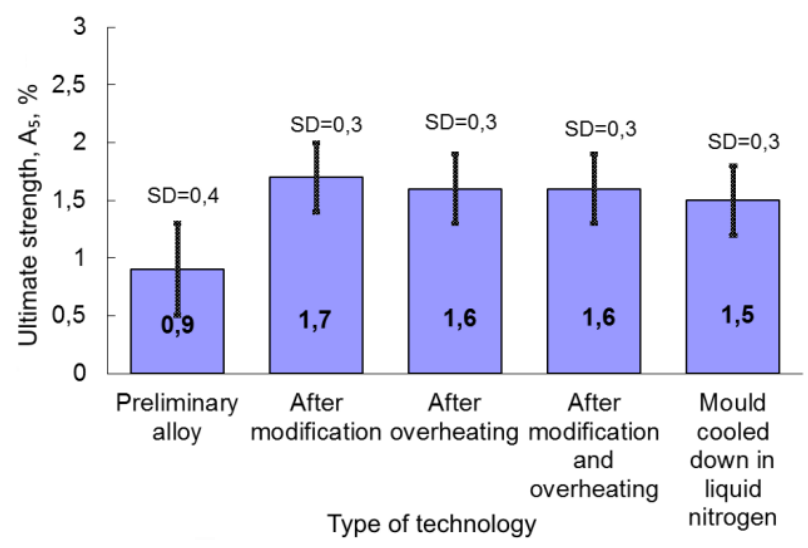

Fig. 5. Ultimate strength $A_{5}$ depending on applied technology

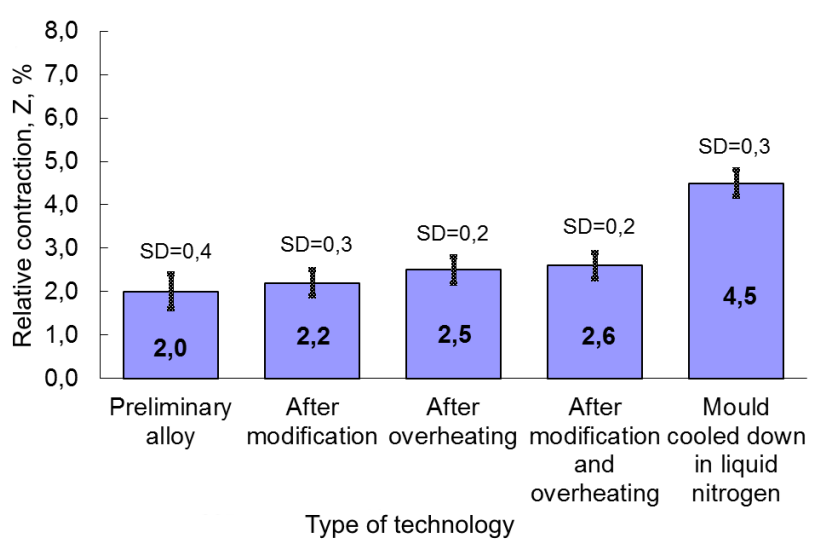

Fig. 6. Relative contraction $Z$ for alloys obtained by different technologies

It is confirmed by the fact of precipitation hardening and enhanced effect of grain boundaries, according to HallPetch theory.

\subsection{Structural investigations}

In order to identify the relationship of achieved hardening effects with structure and phase composition an analysis of microstructure was conducted together with phase analysis using XRD. The best improvement in mechanical properties was achieved for AlSi17Cu4 alloy after overheating and intensive cooling, indeed such sample was the object of further investigation. A significant refinement of primary crystals caused by modification with CuP master alloy was observed, comparing to the microstructure of initial alloy (Fig. 7).

Effect of phosphorus was additionally enhanced by intensive cooling which resulted in refinement of primary crystals of silicon. Initially, silicon formed local irregular elongated clusters in matrix, sometimes even a few millimetres in size, while after chemical modification and rapid cooling silicon crystalized as a small and quite regular polygonal grains regularly dispersed in matrix. That grain refinement should improve machinability of those materials. For the samples, which were exposed to melting with overheating and intensive cooling (the best improvement in mechanical properties), the phase composition was analysed (Fig. 8). 


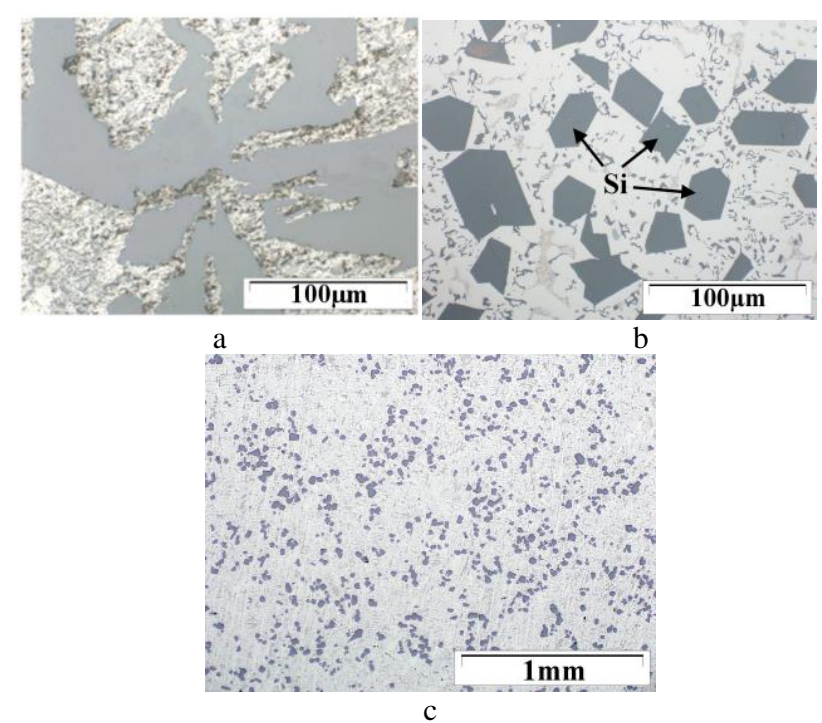

Fig. 7. OM image of AlSi17Cu4 alloy: a-initial alloy; b, $\mathrm{c}$-overheated and subjected to fast crystallisation, different magnification

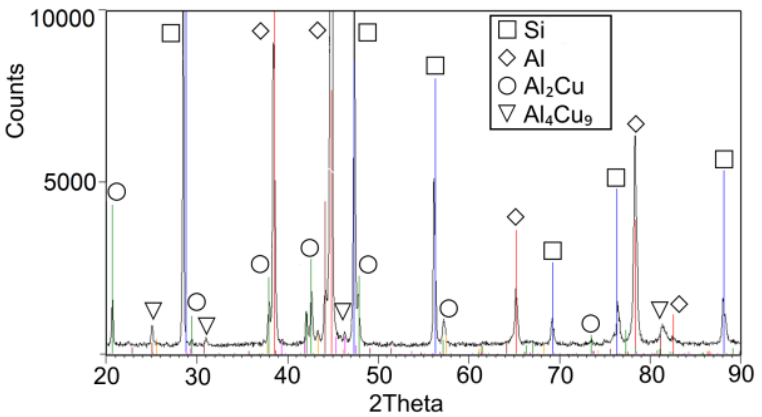

Fig. 8. The XRD pattern of AlSi17Cu4 alloy after chemical modification, overheating and rapid cooling

According to XRD pattern, predominant phases in the material were $\alpha(\mathrm{Al})$ and $\mathrm{Si}$. Moreover, the peaks coming from $\theta\left(\mathrm{Al}_{2} \mathrm{Cu}\right)$ and $\gamma_{1}\left(\mathrm{Al}_{4} \mathrm{Cu}_{9}\right)$ intermetallics were identified. Those results correspond to $\alpha(\mathrm{Al})-\theta\left(\mathrm{Al}_{2} \mathrm{Cu}\right)-\mathrm{Si}$ ternary eutectics indicate that $\mathrm{Al}$ crystalizes from the melt as an $\alpha$-solution, containing some $\mathrm{Cu}$. However, besides $\theta\left(\mathrm{Al}_{2} \mathrm{Cu}\right)$ phase which is component of $\alpha(\mathrm{Al})-\theta\left(\mathrm{Al}_{2} \mathrm{Cu}\right)-(\mathrm{Si})$ ternary eutectic; there is also a non-equilibrium $\gamma_{1}\left(\mathrm{Al}_{4} \mathrm{Cu}_{9}\right)$. Based on several phase equilibrium diagrams [24-26], such $\gamma_{1}$ phase should be expected for much higher concentration of $\mathrm{Cu}$ in the alloy. The $\theta\left(\mathrm{Al}_{2} \mathrm{Cu}\right)$ crystallises at $524-548{ }^{\circ} \mathrm{C}[25,26]$, indeed $\gamma_{1}\left(\mathrm{Al}_{4} \mathrm{Cu}_{9}\right)$ probably crystallises as a second phase after silicon above $873{ }^{\circ} \mathrm{C}$ $[25,26]$, due to rapid cooling because such phase was detected only in samples overheated and rapidly cooled down. The existence of this phase may be the reason of additional improvement in mechanical properties (Fig. 2-Fig. 4). Other reason of increased mechanical properties may be the reduction of grain sizes which is caused by rapid cooling. Microanalysis of identified structural elements in area of identified "copper" eutectics is presented in Fig. 9. The $\alpha(\mathrm{Al})-\theta\left(\mathrm{Al}_{2} \mathrm{Cu}\right)-\mathrm{Si}$ eutectics identified in the microstructure was confirmed by EDS analysis. However, the chemical composition of copperbased precipitates $(\sim 39.1$ at. $\% \mathrm{Cu}$ and $\sim 69.3$ at. $\% \mathrm{Al})$ indicates two phases containing $\mathrm{Cu}: \theta\left(\mathrm{Al}_{2} \mathrm{Cu}\right)$ and
$\gamma_{1}\left(\mathrm{Al}_{4} \mathrm{Cu}_{9}\right)$, and $\mathrm{Al}$. Such phases are consistent with phase composition determined by XRD.

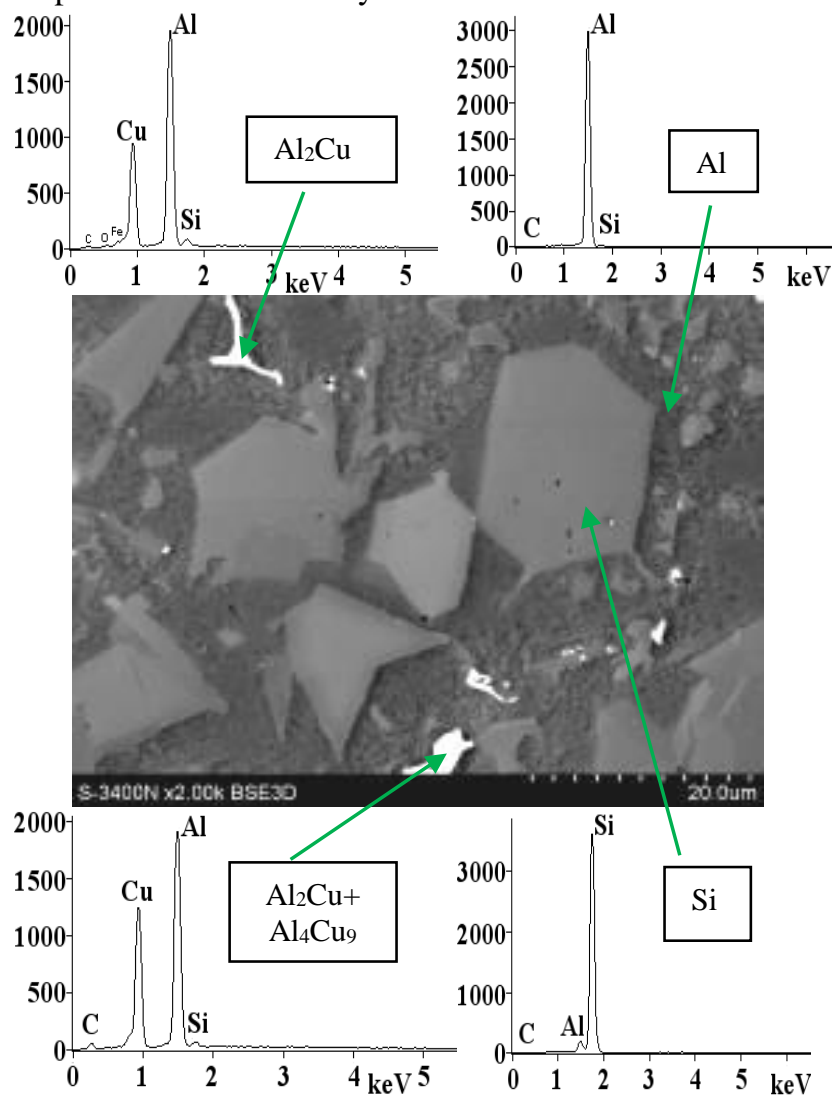

Fig. 9. SEM microstructures and EDS microanalysis of AlSi17Cu4 alloy after overheating and rapid cooling

Considering the deviations from equilibrium conditions during cooling and crystallisation it can be assumed that the phase composition meets the expectations [24-26]. Significant differences in crystallite sizes for each phase certainly result from different melting points. The $\gamma_{1}\left(\mathrm{Al}_{2} \mathrm{Cu}\right)$ precipitates, which undergo crystallisation as last due to the lowest melting point, are very small and they are probably crystallising on $\mathrm{Al}_{4} \mathrm{Cu}_{9}$ phases which are much bigger in size. Explicit statement concerning the mechanism of formation of such phases requires thorough thermodynamic investigations on this system, i.e. ATD, DTA or DSC.

\section{DISCUSSION}

The paper presents characteristics of AlSi17Cu4 alloy modified using different technological processes. Improvement of mechanical properties proved in the paper, could be of significant importance mainly in machine, aerospace, automotive and aviation industries. The optimisation of phase composition and microstructure was supposed to be provided by specially designed method of casting into metal mould submerged in liquid nitrogen. Due to such dynamic heat removal the refined microstructure with significantly improved homogeneity and mechanical properties could be obtained, comparing to conventional casting methods. The investigated alloy was exposed to four different technological processes and each time the improvement of mechanical properties was 
observed at room temperature comparing to reference nonmodified alloy.

It was confirmed that the chosen technological processes (modification with $\mathrm{CuP}$ master alloy; overheating to temperature of $920{ }^{\circ} \mathrm{C}$; overheating with chemical modification; and complex process of modification combined with overheating and rapid cooling) significantly enhanced the mechanical properties. The results were confirmed by hardness measurements and static tension test. It was also proved that the technological stability has improved as indicated by increased repeatability of experimental results, mainly for casting which underwent overheating. Microstructure observations confirmed that a material with refined microstructure was achieved. It can be expected that the yield strength will increase with decreasing grain size, in accordance with Hall-Petch theory [27]. Besides, applied technological processes also improved homogeneity of primary precipitates of silicon in aluminium matrix, which can further explain the small spread of obtained results of mechanical properties. Application of significant overheating can be justified by the change of structure of liquid phase which is responsible for nucleation, growth and formulation of primary silicon in hypereutectic Al-Si alloys. According to several papers published in the last decade [7, 9, 11, 28, 29] after applying of more significant overheating, crystals of primary silicon were significantly reduced and their shape was much closer to regular polyhedrons.

Increase of tested mechanical properties, mainly hardness and tensile strength may have been caused by increased content of copper which causes consolidation of $\alpha$ solution, and crystallises as the intermetallic phases, mainly $\theta\left(\mathrm{Al}_{2} \mathrm{Cu}\right)$ and $\gamma_{1}\left(\mathrm{Al}_{4} \mathrm{Cu}_{9}\right)-($ Fig. 8). According to SEM microstructure (Fig. 10) such precipitates crystallised as an complex eutectics: $\alpha(\mathrm{Al})-\theta\left(\mathrm{Cu}_{2} \mathrm{Al}\right)-\gamma\left(\mathrm{Cu}_{9} \mathrm{Al}_{4}\right)$, which initiates the crystallisation of dendritic precipitates on grain boundaries of aluminium solution.

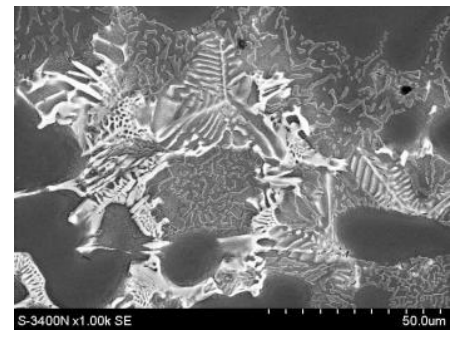

a

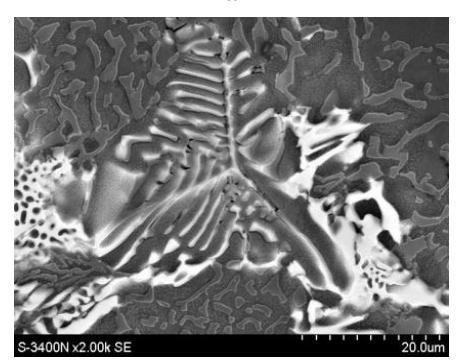

b

Fig. 10. The $\mathrm{Cu}$-rich dendritic structure observed in $\alpha(\mathrm{Al})$ $\theta\left(\mathrm{Cu}_{2} \mathrm{Al}\right)-\gamma_{1}\left(\mathrm{Al}_{4} \mathrm{Cu} 9\right)$ eutectics: a-low magnification; $\mathrm{b}$ - high magnification SEI
However, that tested alloy was not influenced by heat treatment (solution heat treatment and ageing) and that is why appearance of $\gamma_{1}\left(\mathrm{Al}_{4} \mathrm{Cu}_{9}\right)$ phase proves the deviation from thermodynamic equilibrium during cooling and crystallisation.

\section{CONCLUSIONS}

The results of optimisation carried out with $\mathrm{AlSi} 17 \mathrm{Cu} 4$ alloy described in the paper revealed that:

1. Modification of AlSi17Cu4 alloy with copper using applied technological treatments proved to be effective in improvement of mechanical strength and microstructure modification of alloys from $\mathrm{Al}-\mathrm{Si}-\mathrm{Cu}$ system. The technological stability was also successfully improved which was confirmed by good repeatability of achieved results and more homogenous microstructure.

2. Improvement in mechanical properties, particularly hardness and tensile strength could be explained as the effect of increased copper content which strengthened $\alpha(\mathrm{Al})$ solution, which resulted in crystallization of intermetallic phases, for instance $\theta\left(\mathrm{Al}_{2} \mathrm{Cu}\right)$ and $\gamma_{1}\left(\mathrm{Al}_{4} \mathrm{Cu}_{9}\right)$.

3. The most significant improvement in hardness and tensile strength comparing to non-modified condition was observed for samples exposed to overheating to temperature of $920^{\circ} \mathrm{C}$, modified with CuP foundry alloy and rapidly cooled down in the mould submerged in liquid nitrogen.

4. Application of modification processes, overheating and intensive heat removal allowed achievement of grain refinement in the microstructure of tested alloy. Homogenization of alloy in liquid phase ensured by overheating caused creation of countless dispersed precipitates of primary silicon. That resulted in small spread of Si crystallite size in the final microstructure and at the same time it has improved technological stability.

5. It is expected that due to such modified microstructure the machinability of alloys will also improve.

\section{REFERENCES}

1. Zuo, M., Jiang, K., Liu, X. Refinement of Hypereutectic Al-Si Alloy by a New Al-Zr-P Master Alloy Journal of Alloys and Compounds 503 2010: pp. L26-L30. http://dx.doi.org/10.1016/j.jallcom.2010.05.017

2. Robles Hernandez, F.C., Sokolowski, J.H. Thermal Analysis and Microscopical Characterization of Al-Si Hypereutectic Alloys Journal of Alloys and Compounds 419 (1) 2006: pp. $180-190$ http://dx.doi.org/10.1016/j.jallcom.2005.07.077

3. Sjölander, E., Seifeddine, S. The Heat Treatment of Al-Si$\mathrm{Cu}-\mathrm{Mg}$ Casting Alloys Journal of Materials Processing Technology 210 (10) 2010: pp. $1249-1259$. http://dx.doi.org/10.1016/j.jmatprotec.2010.03.020

4. Heard, D.W., Donaldson, I.W., Bishop, D.P. Metallurgical Assessment of a Hypereutectic Aluminum-silicon P/M Alloy Journal of Materials Processing 209 (18) 2009: pp. $5902-5911$. 
5. Szajnar, J., Wróbel, T. Inoculation of Pure Aluminum with an Electromagnetic Field Journal of Manufacturing Processes 10 (2) 2008, pp. 74-81.

6. Li, P., Nikitin, V.I., Kandalova, E.G., Nikitin, K.V. Effect of Melt Overheating, Cooling and Solidification Rates on Al-16wt.\%Si Alloy Structure Materials Science and Engineering: A 332 (1) 2002: pp. 371-374. http://dx.doi.org/10.1016/S0921-5093(01)01864-0

7. Wang, J., He, S., Sun, B., Guo, Q., Nishio, M. Grain Refinement of Al-Si alloy (A356) by Melt Thermal Treatment Journal of Materials Processing Technology 141 (1) 2003: pp. 29-34.

8. Wang, L., Bian, X., Liu, J. Discontinuous Structural Phase Transition of Liquid Metal and Alloys (1) Physics Letters A 326 (5-6) 2004: pp. 429-435.

9. Wang, W., Bian, X., Qin, J., Syliusarenko, S.I. The Atomic-structure Changes in Al-16 pct Si Alloy above the Liquidus Metallurgical and Materials Transactions A 31 (9) 2005: pp. 2000-2163.

10. Zuo, M., Liu, X.F., Sun, Q.Q., Jiang, K. Effect of Rapid Solidification on the Microstructure and Refining Performance of an Al-Si-P Master Alloy Journal of Materials Processing Technology 209 (15) 2009: pp. 5504-5508.

http://dx.doi.org/10.1016/j.jmatprotec.2009.05.005

11. Xu, C.L., Jiang, Q.C. Morphologies of Primary Silicon in Hypereutectic Al-Si Alloys with Melt Overheating Temperature and Cooling Rate Materials Science and Engineering: A 437 (2) 2006: pp. 451-455.

12. Wang, J., He, S., Sun, B., Li, K., Shu, D., Zhou, Y. Effects of Melt Thermal Treatment on Hypoeutectic Al-Si Alloys Materials Science and Engineering: A $338(1-2)$ 2002: pp. $101-107$.

13. Uzun, O., Karaaslan, T., Gogebakan, M., Keskin, M. Hardness and Microstructural Characteristics of Rapidly Solidified Al-8-16 wt.\% Si Alloys Journal of Alloys and Compounds 376 (1) 2004: pp. 149-157. http://dx.doi.org/10.1016/j.jallcom.2004.01.017

14. Xu, C.L., Wang, H.Y., Qiu, F., Yang, Y.F., Jiang, Q.C. Cooling Rate and Microstructure of Rapidly Solidified Al20 wt.\% Si Alloy Materials Science and Engineering: A 417 (1) 2006: pp. $275-280$. http://dx.doi.org/10.1016/j.msea.2005.10.040

15. Nikanorov, S.P., $\quad$ Volkov, M.P., Gurin, V.N., Burenkov, Yu.A., Derkachenko, L.I., Kardashev, B.K., Regel, L.L., Wilcox, W.R. Structural and Mechanical Properties of Al-Si Alloys Obtained by Fast Cooling of a Levitated Melt Materials Science and Engineering: A 390 (1-2) 2005: pp. 63-69.

16. Binczyk, F., Piątkowski, J. New View on the Impact of Phosphorus in the Development of the Primary Structure
Silumin Hypereutectic Archives of Material Science 21 (3-4) 2000: pp. 199-213 (in Polish).

17. Dercz, G., Piątkowski, J. Rietveld Quantitative and Structural Analysis of the Al-W Master Alloy for Silumina Modification Solid State Phenomena 163 2010: pp. $161-164$.

18. Górny, Z., Sobczak, J. Non-ferrous Metals Based Novel Materials in Foundry Practice ZA-PIS Krakow 2005, p. 85.

19. Piątkowski, J., Gajdzik, B., Matuła, T. Crystallization and Structure of Cast A390. 0 Alloy with Melt Overheating Temperature Metalurgija 51 (3) 2012: pp. 321-324.

20. Piątkowski, J., Binczyk, F. Reasons for Extending the Hardness Silumin AlSi17 with Alloy Additives after Heat Treatment Archives of Material Science 23 (4) 2002: pp. 337-341 (in Polish).

21. Piątkowski, J. The Effect of Al-17wt.\% Si Alloy Melt Overheating on Solidification Process and Microstructure Evolution Solid State Phenomena 176 2011: pp. 29-34.

22. Piątkowski, J. Effect of Overheating Degree on the Solidification Parameters of AlSi17CuNiMg Silumin Archives of Foundry Engineering 10 (2) 2010: pp. $103-107$.

23. Latief, F.H., Sherif, E.S.M. Effects of Sintering Temperature and Graphite Addition on the Mechanical Properties of Aluminum Journal of Industrial and Engineering Chemistry 18 (6) 2012: pp. 2129-2134.

24. Villars, P., Prince, A., Okamoto, H. Handbook of Ternary Alloy Phase Diagrams, vol.3, ASM International, Materials Park, OH, 1995, pp. $3331-3333$.

25. Subramanian, P.R., Chakrabarti, D.J., Laughlin, D.E. Phase Diagrams of Binary Copper Alloys, Monograph series on Alloy Phase Diagrams, ASM International, Materials Park, OH, 1994: pp. 18-37.

26. Petzow, G., Effenberg, G. Ternary Alloys, A Comprehensive Compendium of Evaluated Constitutional Data and Phase Diagrams, vol. $5 \mathrm{Al}-\mathrm{Cu}-\mathrm{S}$ to $\mathrm{Al}-\mathrm{Gd}-\mathrm{Sn}$, Weinheim, Germany, 1992: pp. $11-18$.

27. Ashby, M. F., Dawid, R. H., Jones, H. Engineering Materials, Part 2, Shaping Structure and Properties, Choice of Materials, WNT, Warszawa 1996: pp. 157-185.

28. Dai, H.S., Liu, X.F. Refinement Performance and Mechanism of an Al-50Si Alloy Materials Characterization 59 (11) 2008: pp. 1559-1563. http://dx.doi.org/10.1016/j.matchar.2008.01.020

29. Dahlborg, U., Besser, M., Calvo-Dahlborg, M., Cuello, G., Dewhurst, C.D., Kramer, M.J., Morris, J.R., Sordelet, D. J. Structure of Molten Al-Si Alloys Journal of Non-Crystalline Solids 353 (32) 2007: pp. 3005-3010. http://dx.doi.org/10.1016/j.jnoncrysol.2007.05.031 